\title{
LETRAMENTO ESCOLAR: REFLEXÕES SOBRE A PRODUCְ̃̃O ESCRITA DE ADOLESCENTES
}

\author{
Valéria Barbosa de Resende* \\ Universidade Federal de Minas Gerais (UFMG) \\ Francisca Izabel Pereira Maciel"* \\ Universidade Federal de Minas Gerais (UFMG)
}

RESUMO: O presente texto apresenta uma pesquisa desenvolvida em 2007, em uma escola da Rede Municipal de Belo Horizonte, envolvendo 42 adolescentes com idades entre 12 e17 anos, com trajetórias marcadas pelo fracasso escolar. A partir da observação participante, foram organizados e analisados eventos de letramento. Apresentaremos aqui a análise de dois gêneros textuais produzidos pelos adolescentes, anúncio e bilhete, tomando-se como perspectiva teórica a linguagem em sua natureza social e dialógica, produzida enquanto ação humana. A partir das análises constatou-se que os alunos liam e produziam textos na sala de aula, mediados pelas ações da professora, que colocava à disposição dos alunos diversos gêneros textuais, como também incentivava a leitura coletiva dos textos produzidos por eles. Observou-se também a participação dos adolescentes na redefinição das funções da escrita.

Palavras-chave: Escrita. Gêneros textuais. Adolescentes.

http://dx.doi.org/10.1590/0102-4698133997

"Doutora em Educação pela Universidade Federal de Minas Gerais, professora adjunta da Faculdade de Educação/ UFMG, pesquisadora do Centro de Alfabetização Leitura e Escrita (CEALE/FAE/UFMG). E-mail: valeriabr@ufmg.br.

" Doutora em Educação pela Universidade Federal de Minas Gerais, Pós-doutorado pela PUC/SP, Professora Associada da Faculdade de Educação/UFMG, pesquisadora do Centro de Alfabetização Leitura e Escrita e (CEALE) FAE/UFMG). E-mail: emaildafrancisca@gmail.com. 


\section{SCHOOL LITERACY: REFLECTIONS ABOUT TEENAGERS'S WRITING PRODUCTION}

ABSTRACT: This paper presents a research, developed in 2007 in a municipal school of Belo Horizonte involving 42 teenagers aged between 12 and 17 years with paths marked by school failure. From the participant point of view, literacy events were organized and analyzed. Here we present the analysis of two kinds of texts produced by teenagers: advertising and note, taking as theoretical perspective language in its social and dialogical nature, produced as human action. From the analysis it was found that students read and produced texts in the classroom watched by the actions of the teacher who placed at the disposal of the students various textual genres, but also encouraged the collective reading of texts produced by them. We also observed the teenagers' participation in the redefinition of the functions of writing.

Keywords: Writing. Textual gender. Teenagers.

\section{INTRODUCุÃO}

O presente artigo pretende discutir uma temática recorrente nas escolas públicas brasileiras envolvendo a produção escrita de adolescentes. É comum ouvirmos dos professores o seguinte comentário: "Os adolescentes não sabem escrever". Esse discurso, muitas vezes, é corroborado pelos resultados das avaliações externas, principalmente pelo Exame Nacional do Ensino Médio - ENEM, que afere competências envolvendo a produção escrita dos adolescentes. A título de exemplo, podemos citar os resultados do ENEM (2014), em que, segundo dados do INEP (2015), das 6.193 .565 redações corrigidas, apenas 250 estudantes alcançaram nota máxima. Mais de 529 mil candidatos tiveram a prova anulada, dos quais 217 mil não contemplaram, nos seus textos, o tema proposto e 248 mil candidatos entregaram a prova em branco. Não pretendemos fazer aqui uma análise das condições envolvidas no momento da realização das provas e nem apresentar críticas sobre esse tipo de exame. É fato que os resultados do ENEM acabam por gerar uma discussão sobre o fracasso da escola na formação de alunos produtores de textos. Por outro lado, constatamos que a maioria desses adolescentes já se apropriou da tecnologia da escrita, conforme definição de Soares (2003), ou seja, já compreende o sistema de escrita alfabética. Entretanto, esses conhecimentos não são suficientes para o aluno produzir plenamente os gêneros textuais solicitados pela escola e exigidos nas avaliações externas, como também para atender às demandas sociais do letramento. 
Assim, evidencia-se que o problema não está vinculado ao processo de alfabetização propriamente dito, ou seja, ao domínio das relações entre "os sons da fala e as letras da escrita, à mecânica da escrita/leitura", mas a questões que envolvem "o desenvolvimento de competências de leitura e escrita” (ROJO, 2009, p. 60).

Há décadas discutimos novas metodologias de alfabetização e, desde os anos 1980, passamos a conviver com o conceito de letramento, que diz respeito às práticas sociais de leitura e escrita. $\mathrm{O}$ conceito de letramento ressignificou o conceito de alfabetização e produziu mudanças profundas na prática pedagógica de alfabetização. Assim, o conceito de alfabetização, além de designar a aprendizagem inicial da leitura e da escrita, envolve também a capacidade da criança de ler e produzir gêneros textuais variados com diversos propósitos e em variadas esferas de interação social.

Ainda nos anos 1980, uma nova orientação metodológica foi introduzida e aceita no Brasil, que é a de ensinar a língua por meio de gêneros textuais, ao invés de focar as propriedades gerais dos textos, baseadas na classificação tipológica de narração, descrição e dissertação. Essa nova perspectiva foi amplamente discutida na época do lançamento do livro organizado por Geraldi, em 1984, intitulado O texto na sala de aula: leitura e produção, publicação considerada marco de consagração do texto como objeto de ensino. Essa perspectiva depois viria a ser reforçada nos Parâmetros Curriculares Nacionais de 1997, em que, segundo Rojo e Cordeiro (2004, p. 11), "convoca-se a noção de gêneros (discursivos ou textuais) como um instrumento melhor que o conceito de tipo para favorecer o ensino de leitura e de produção de textos escritos e também orais".

Em consonância com essa perspectiva e diante da multiplicidade de gêneros textuais que circulam no nosso contexto social, algumas questões são pertinentes para se pensar o ensino da língua por meio de gêneros textuais: 1) Quais gêneros textuais priorizar e eles pertencentes a quais esferas da comunicação social? 2) É possível organizar uma sequência didática na perspectiva dos gêneros? 3) Como os adolescentes interagem com os gêneros textuais propostos pela professora?

Partindo dessa problemática e orientados por essas questões, desenvolvemos uma pesquisa em 2007 que contou com a colaboração de uma professora e 42 adolescentes, com idades entre 12 e 17 anos, sendo a maioria proveniente do aglomerado Morro das Pedras, em Belo Horizonte. Esse grupo de estudantes participava do projeto, denominado na época "Rede do $3^{\circ}$ ciclo", organizado pela Secretaria 
Municipal de Educação de Belo Horizonte, Minas Gerais, cujo objetivo era incluir esses adolescentes, que viviam em uma realidade de vulnerabilidade social, na prática escolar do $3^{\circ}$ ciclo $^{2}$.

O projeto denominado "Rede do $3^{\circ}$ ciclo - Projeto tempo integral" surgiu a partir dos desdobramentos do "Projeto Emergencial de Alfabetização para o $3^{\circ}$ ciclo", criado em 2003, pela Secretaria Municipal de Educação de Belo Horizonte. Esse projeto tinha por objetivo responder às demandas de alfabetização e letramento dos alunos do $3^{\circ}$ ciclo e contava com a participação de professores alfabetizadores que lecionavam no $1^{\circ}$ ciclo. Além dos professores, o projeto contava com o apoio dos "agentes culturais", que eram assim designados por assumirem a tarefa de fazer a ponte entre a escola e a cultura juvenil. Esses jovens, pertencentes às comunidades dos alunos, cursavam o ensino médio ou curso superior e se engajavam nas práticas pedagógicas do projeto, oferecendo oficinas envolvendo artes plásticas, música, dança e percussão.

$\mathrm{Na}$ época da pesquisa, em 2007, o projeto desenvolvia a maior parte de suas atividades no espaço escolar e envolvia somente os professores que atuavam no $3^{\circ}$ ciclo. Essa mudança visava implicar as escolas que atendiam alunos do $3^{\circ}$ ciclo no trabalho de letramento e direcioná-las para a construção de práticas pedagógicas sensíveis às especificidades da juventude. Outro fator que contribuiu para as mudanças do projeto diz respeito ao resultado do diagnóstico relativo às questões de alfabetização, indicando que a maioria dos alunos já dominava a base alfabética e que os problemas apresentados estavam relacionados à produção de textos e à ortografia.

Para a seleção da escola a ser pesquisada, nos orientamos pela indicação da coordenadora do "Projeto Rede do $3^{\circ}$ ciclo" da Secretaria Municipal de Educação de Belo Horizonte, que acompanhou o projeto na escola em 2006 e considerou a experiência inovadora para o $3^{\circ}$ ciclo. Entre os aspectos inovadores, a coordenadora citou a produção de um jornal da Rede do $3^{\circ}$ ciclo da escola, a produção escrita contextualizada e a oficina de percussão. A professora que coordenava o projeto na escola concordou em participar da pesquisa e afirmou que organizava as atividades de ensino da língua portuguesa a partir de leitura e produção de gêneros textuais. Esse aspecto da prática da professora do projeto foi decisivo para a escolha da escola, pois alinhava-se com um dos objetivos da pesquisa: observar, descrever e analisar eventos e práticas de letramento escolar, tendo como foco a produção escrita de gêneros textuais. 
Para esse estudo, adotamos os procedimentos relativos à pesquisa qualitativa, com inspiração etnográfica, com o intuito de aprender o ponto de vista dos pesquisados, conferindo dignidade às experiências vivenciadas em campo e aceitando ser "afetado" por elas (GOLDMAN, 2003), tomando como recurso metodológico a observação participante por ser a principal ferramenta do paradigma etnográfico. A opção por esse paradigma diz respeito ao modo como o pesquisador se posiciona diante dos sujeitos pesquisados, com o intuito de captar os significados que têm as ações e os eventos para as pessoas ou para os grupos estudados. Em todas as sociedades, as pessoas usam sistemas complexos de significados para organizar seu comportamento, entender a sua própria pessoa e os outros e dar sentido ao mundo em que vivem (SPRADLEY, 1979). A observação participante é assim definida, porque parte do princípio de que o pesquisador tem sempre um grau de interação com a situação estudada, afetando-a e sendo por ela afetado. "Isso implica uma atitude de constante vigilância, por parte do pesquisador, para não impor seus pontos de vista, crenças e preconceitos" (ANDRÉ, 2005, p. 26). Assim foi possível conviver com a professora do projeto e os estudantes-adolescentes durante nove meses. Semanalmente, observamos as aulas desenvolvidas no projeto que envolviam a recepção e a produção de gêneros textuais.

\section{EVENTOS E PRÁTICAS DE LETRAMENTO: CONCEPC̣ÃO TEÓRICA}

Optamos pelo uso do termo "eventos de letramento", cunhado por Heath (1982, citado por SOARES, 2003, p. 105), definido pela autora como sendo "as situações em que a língua escrita é parte integrante da natureza da interação entre participantes e de seus processos de interpretação". Trata-se de situações mediadas pelo texto escrito, seja através da interação face a face ou da interação em que o interlocutor está ausente.

Além do conceito de eventos de letramento, adotou-se outro conceito relacionado a ele, o de "práticas de letramento", que diz respeito aos comportamentos exercidos pelos participantes num determinado evento de letramento, considerando os contextos sociais e culturais que configuram e determinam sua interpretação e dão sentido aos usos da leitura e/ou da escrita naquela particular situação (SOARES, 2003). 
No sentido de melhor elucidar os conceitos de eventos e práticas de letramento, vamos apresentar alguns exemplos cunhados de Kleiman (1996) e Soares (2003). Kleiman (1996) discute como um mesmo evento de letramento, por exemplo, o ato de contar histórias para as crianças antes de dormir, pode desenvolver padrões diferenciados para extrair significado da escrita. A autora apoia-se em estudos realizados por Heath $(1982,1983)$ para analisar como as famílias com nível de escolarização elevado elaboravam perguntas sobre os livros, encorajavam a criança a inventar histórias e assumiam uma atitude generalizada de tratar o livro como uma diversão. No grupo de baixa escolarização, observou-se que o adulto recontava de forma simplificada as histórias, não elaborava perguntas e as crianças não eram encorajadas a inventar histórias. Neste caso, notou-se que apenas alguns membros da comunidade exerciam o papel de contadores de histórias e, além disso, as histórias valorizadas pela comunidade estavam relacionadas aos relatos factuais que serviam para enfatizar alguma lição de moral. Assim, a pesquisa realizada por Kleiman (1996) apontou que as práticas de letramento mudam segundo o contexto.

Soares (2003) apresenta exemplos de situações em que um mesmo evento, por exemplo, a leitura de jornal, pode gerar interações diferenciadas, dependendo do contexto. Quando lemos um jornal em nossa casa com interesse específico de buscar uma informação, é diferente de quando levamos esse mesmo portador para a sala de aula para que uma notícia seja lida e interpretada pelos alunos, ou seja, para ensinar a ler e interpretar uma notícia jornalística. Evidenciamse, assim, as diferenças entre letramento escolar e letramento social, considerando-se a natureza técnica e individual do letramento escolar em oposição ao letramento social, que ocorre fora da escola.

O letramento escolar é um tipo de prática de letramento que desenvolve um tipo de habilidade, não outros. Geralmente, na escola, há uma valorização de habilidades individuais, além de consideraremse as atividades de leitura e de escrita como neutras, universais e distanciadas tanto do professor quanto do aluno, como se estes fossem receptores passivos (modelo autônomo de letramento). Street (1995, citado por SOARES, 2003, p. 107) denomina esse processo de "Pedagogização do letramento" - processo pelo qual a leitura e a escrita, no contexto escolar, integram eventos e práticas sociais específicas, associados à aprendizagem, de natureza bastante diferente dos eventos e práticas associadas a objetivos e concepções não escolares. Segundo Soares (2003, p. 107), "essa pedagogização da 
leitura e da escrita - dos eventos e práticas de letramento - é, porém, inerente à necessária e inevitável escolarização de conhecimentos e práticas.” Já o modelo ideológico de letramento oferece uma alternativa conceitual que nega a neutralidade da escrita e compreende seus efeitos, considerando as questões sociais, culturais e de poder.

Soares (2003) aponta que as práticas sociais de letramento são transformadas em práticas de letramento a ensinar, que são aquelas que "a escola seleciona para torná-las objetos de ensino" (SOARES, 2003, p.108). Trata-se, pois, tanto de escrever para aprender a escrever (práticas de letramento ensinadas), quanto para usar socialmente a leitura e a escrita (práticas de letramento adquiridas).

Entende-se que a relação entre as práticas de letramento ensinadas e as práticas de letramento adquiridas não se dá de forma linear, mas em função do contexto social em que essas práticas aparecem. Para essa análise, será retomada a explicação de Street (2003) referente ao modelo ideológico de letramento, em que a leitura e a escrita encontram-se vinculadas ao contexto cultural e às estruturas de poder de uma sociedade, ou seja, para o autor, o conceito de letramento ultrapassa a mera aquisição de uma tecnologia e é atravessado pelo viés político-ideológico. Segundo Street (2003, p. 77, tradução nossa):

A pesquisa do NLS desafia esta visão (letramento autônomo) e sugere que, na prática, a alfabetização varia de um contexto ao outro e de uma cultura a outra e, por esse motivo, possui efeitos de letramento diferentes em condições diferentes. O modelo autônomo impõe simplesmente as concepções ocidentais de letramento sobre outras culturas ou em um mesmo país de uma classe ou de um grupo cultural sobre outro. ${ }^{3}$

Isso significa dizer que diferentes segmentos sociais fazem usos distintos da linguagem escrita, assim, há diferentes formas de ser letrado. Por exemplo, para um adolescente que reside na cidade de Belo Horizonte, em que há uma circulação intensa da matéria escrita em diferentes contextos, as competências de leitura e de escrita exigidas diferem, se comparadas às possibilidades de interação com a cultura escrita de adolescentes que vivem em zonas rurais do interior de Minas Gerais.

Em outra direção, corroborando o pressuposto de Street (2003), é possível também afirmar que um sujeito com pouca escolaridade, inserido em um meio com práticas letradas restritas, use a escrita e a ressignifique. Como exemplo, a pesquisa de Thies e Peres (2009), que analisa práticas de moradores de zonas rurais da região sul do Rio Grande do Sul, evidencia letramentos em contextos 
não escolares. As autoras analisam "os diários de agricultores que, através de seus registros, ressignificam sua história, realizando observações importantes quanto ao trabalho da lavoura, ao tempo e ao clima, ao lazer e aos acontecimentos pessoais e sociais da vida comunitária" (THIES; PERES, 2009, p. 221).

Dessa forma, verifica-se que os eventos e as práticas de letramento são mediados pelos gêneros discursivos. Como enfatiza Bakhtin (2003, p.265), "a língua passa a integrar a vida através de enunciados concretos (que se realizam); é igualmente através de enunciados concretos que a vida entra na língua". Esse argumento, elaborado por Bakhtin por volta de 1920, mas bem pertinente para se pensar as práticas de leitura e escrita da atualidade, inspirado no paradigma sócio-histórico e dialético da linguagem, baseia-se no pressuposto de que a língua se realiza, ao mesmo tempo, em um contexto social imediato (microinteração) e mais amplo (estruturas sociais). Para Bakthin (1988), a língua se realiza por meio de enunciados concretos (orais e escritos), cuja natureza essencial é social.

Considerando-se a teoria da enunciação e para efeito de análise dos eventos de letramento que serão apresentados aqui, entende-se por gêneros textuais os modos de organização da linguagem em uso. O estudo dos gêneros discursivos considera, sobretudo, a natureza do enunciado em sua diversidade e nas diferentes esferas da atividade.

Com relação ao referencial bakhtiniano, Fairclough (2001) utiliza o termo gênero para designar um conjunto de convenções relativamente estável, socialmente aprovado, como a conversa informal, o momento da compra de produtos em uma loja, uma entrevista de emprego, um documentário de televisão, um poema ou um artigo científico. Segundo o autor, um gênero implica não somente um tipo particular de texto, mas também processos particulares de produção, distribuição e consumo.

Para Schneuwly e Dolz (2004), na escola “o gênero não é mais um instrumento de comunicação somente, mas é, ao mesmo tempo, objeto de ensino e aprendizagem" (SCHNEUWLZ; DOLZ, 2004, p.76). Quando os gêneros são transportados para outro lugar social, por exemplo, da mídia para a escola, eles sofrem uma transformação. Visando minorar as dificuldades provenientes dessa situação, os autores propõem a elaboração de "modelos didáticos de gêneros” (SCHNEUWLZ; DOLZ, 2004, p. 81).

$\mathrm{Na}$ análise das condições imediatas de produção, serão considerados os aspectos elencados por Dolz, Noverraz e Schneuwly 
(2004). Para os autores, uma sequência didática adequada para a produção de gêneros escolares deverá evidenciar o gênero textual a ser abordado, levando para a sala de aula vários modelos do gênero visado; os autores também enfatizam que é preciso identificar quem é o interlocutor do texto, o suporte em que o texto vai se materializar (folheto, cartaz, livro etc.) e quem participará da produção, se todos os alunos da turma, grupos ou os alunos individualmente.

Então, para Schneuwly e Dolz (2004), uma sequência didática é uma importante ferramenta para se trabalhar gêneros textuais na escola, porque organiza as atividades escolares em torno de um gênero textual oral ou escrito, opondo-se a práticas tradicionais das atividades em folhas avulsas ou da realização aleatória de exercícios nos livros didáticos, sem definição e progressão de habilidades a serem trabalhadas. Esses autores apresentam quatro componentes de uma sequência didática: 1) apresentação da tarefa que será realizada, com exposição dos objetivos; 2) produção inicial do gênero textual que será trabalhado; 3) proposição de módulos ou oficinas para sistematizar e aprofundar aspectos relacionados à estrutura composicional, ao conteúdo temático, ao estilo e à função do gênero textual a ser produzido; e 4) a produção final, que serve, também, como avaliação dos aspectos trabalhados nos módulos ou oficinas.

As orientações de Schneuwly e Dolz (2004) serviram de suporte para a escolha da escola, ou seja, buscamos selecionar uma prática pedagógica que se aproximasse do modelo proposto pelos autores. A seguir, apresentaremos o contexto escolar e o modo como foram feitas as observações.

\section{CONTEXTO DE PRODUÇÃO DOS EVENTOS E PRÁTICAS DE LETRAMENTO}

A escola pesquisada está localizada na região centro-sul de Belo Horizonte e atende estudantes provenientes das regiões do Morro das Pedras, Cascalho, Vila São Jorge, Nova Granada e Serra. Em 2007, no turno da manhã funcionava o projeto "Rede do $3^{\circ}$ ciclo" e as turmas do Ensino Médio; no período da tarde, funcionavam as turmas regulares do $3^{\circ}$ ciclo.

As observações iniciaram-se em março de 2007, com periodicidade semanal, sempre às terças-feiras. Havia inscritos no projeto 60 adolescentes, com idades entre 12 e 17 anos, contudo, nem todos compareciam às aulas diariamente. Assim, a média de alunos que participavam das atividades às terças-feiras girava em 
torno de 42 adolescentes. Nesse dia, os alunos se revezavam em dois grupos: atividades de leitura e escrita e oficina de teatro. A professora responsável pelas atividades de leitura e escrita é formada em Letras e atuava no projeto desde a sua criação na escola, em 2005, e tinha vinte anos de magistério na Rede Municipal de Belo Horizonte.

$\mathrm{Na}$ pesquisa realizada, a professora procurava levar para a sala de aula uma diversidade de gêneros textuais, com a intenção de ampliar as experiências discursivas dos adolescentes. Segundo a professora:

pra fazer um trabalho legal, a gente tem que trabalhar com textos que te digam alguma coisa, que têm algum significado para os meninos também. Então, se você tem uma turma $\mathrm{x}$, você vai ver que determinado assunto vai interessar mais, que tem mais a ver com a vida deles. Se eu pego um texto que não tem nada a ver com a vida dele, ele não vai ter o menor interesse por aquilo mesmo não, então me preocupo muito. (Professora, Diário de campo, 10/04/2007)

Além disso, a professora desenvolvia uma atitude de escuta, aproximando-se dos adolescentes. Os fragmentos a seguir exemplificam as diferenças apontadas pelos alunos sobre o trabalho desenvolvido no projeto (turno da manhã) e nas turmas regulares do $3^{\circ}$ ciclo (turno da tarde), principalmente relacionadas à organização das atividades e às condições de produção textual:

[...] a dinâmica, aqui [no projeto], você lê e escreve por alguma coisa, por exemplo: vê o filme e tem que escrever o que a gente achou do filme. Lá não, lá tem que escrever porque tipo um exercício, porque ganha ponto. (Erick)

[...] aqui no projeto é mais fácil, sempre tem alguma coisa pra dar ideia, a tarde, não! Tem que fazer já. É... da minha janela, como é que é? “O que vejo da minha janela. Um texto de 120 palavras, começando assim: da minha janela vejo não sei o quê". Mas, tinha que fazer sem escrever a palavra... da minha janela vejo, não pode falar veja, aí eu coloquei da minha janela observo. (Patrick)

De tarde a gente faz as atividades do livro didático e no projeto (manhã) a gente aprende mais, explica mais, explica direito. (Sabrina)

O projeto é bom, é legal, não é igual de tarde, aqui a gente aprende na brincadeira, de tarde é tudo na base da chicotada, tem que ser na linha certa. (Jane)

A professora [do projeto] se impõe mais, ela dá mais informações sobre o assunto, ela para, brinca com a gente. (Júnior)

A professora [do projeto] ajuda a gente, tem gente que nem sabe ler direito, sabe? Ela ajuda, ensina, o menino que nem sabe fazer as coisas. (Miriam)

Aprendi a ler aqui [no projeto], eu sabia ler um tiquinho, mas gaguejando, engolia o M, R. Aqui dá até mais vontade de fazer as coisas. (Maria)

A partir da fala dos adolescentes, constatamos as diferenças no trabalho de produção textual desenvolvido nas turmas regulares do $3^{\circ}$ 
ciclo e no projeto "Rede do $3^{\circ}$ ciclo" (Quadro 1), diferenças estas que afetaram de forma significativa a relação dos adolescentes com a escrita.

\section{QUADRO 1}

Contrastando a percepção da escrita pelos adolescentes no projeto e nas $t$ urmas regulares do $3^{\circ}$ ciclo

\begin{tabular}{|c|c|}
\hline $\begin{array}{l}\text { Comentários dos adolescentes acerca } \\
\text { da produção escrita desenvolvida no } \\
\text { projeto "Rede do } 3^{\circ} \text { ciclo" }\end{array}$ & $\begin{array}{c}\text { Comentários dos adolescentes acerca } \\
\text { da produção escrita desenvolvida nas } \\
\text { turmas regulares do } 3^{\circ} \text { ciclo }\end{array}$ \\
\hline $\begin{array}{c}\text { Escrever para opinar - "escrever o } \\
\text { que achou do filme" }\end{array}$ & Escrever para "ganhar ponto" \\
\hline $\begin{array}{l}\text { Tema contextualizado - } \\
\text { "fazer um texto" }\end{array}$ & Tema livre, redação \\
\hline $\begin{array}{l}\text { "Sempre tem alguma coisa } \\
\text { pra dar ideia" }\end{array}$ & "Sem inspiração" \\
\hline $\begin{array}{c}\text { "A gente aprende mais, explica mais, } \\
\text { explica direito" }\end{array}$ & $\begin{array}{l}\text { "A gente faz as atividades do } \\
\text { livro didático" }\end{array}$ \\
\hline "Aprender na brincadeira" & "Aprender na base da chicotada" \\
\hline $\begin{array}{l}\text { “Dá mais informação sobre o assunto, } \\
\text { ela para, brinca com a gente" }\end{array}$ & "Tem que fazer já, com 120 palavras" \\
\hline $\begin{array}{l}\text { "Aprendi a ler aqui". "Aqui dá até mais } \\
\text { vontade de fazer as coisas" }\end{array}$ & “Tem que ser na linha certa” \\
\hline
\end{tabular}

Fonte: Elaborado pelas autoras deste artigo.

A partir do discurso dos adolescentes, percebemos algumas diferenças entre as aulas realizadas no projeto (turno da manhã) e as aulas das turmas regulares (turno da tarde). Fica evidente que a professora do projeto preocupava-se em definir alguns aspectos relacionados às condições de produção textual, principalmente, no que diz respeito ao gênero e ao assunto: "escrever o que a gente 
achou do filme"; "ela dá mais informações sobre o assunto". Isso ocorre em contraposição a uma metodologia que define apenas o valor da atividade, o tempo e a quantidade de palavras que deve ser usada - "um texto de 120 palavras". Além disso, há diferenças na maneira de lidar com as dificuldades dos alunos e de se relacionar com eles: "A professora ajuda a gente"; "Eu sabia ler um tiquinho, mas gaguejando, engolia o M, R", "aprendi a ler aqui [no projeto]". "De tarde é tudo na base da chicotada".

Com relação às condições de produção, é preciso compreender que o processo de produção textual envolve uma série de aspectos que, necessariamente, devem ser considerados e planejados. Isso porque a opção pela escrita como forma de interlocução não ocorre por acaso, mas acontece em função de determinadas situações. Geraldi (1997) aponta que são diversos os fatores condicionantes para a produção escrita, dentre eles: assumir a autoria ${ }^{4}$ do texto, ter o que dizer sobre determinado tema, ter razões para dizer e escolher estratégias para dizer.

Ao produzir um texto, o autor deve ter uma ideia de quem vai lê-lo, conhecendo, mais ou menos, os interesses e os conhecimentos prévios de seu leitor, para planejar aquilo que pretende dizer e dizê-lo de forma mais adequada e com maior possibilidade de ser compreendido. Quando escrevemos um texto, o tema não pode, por si só, ser considerado como suficiente para a produção textual. $\mathrm{O}$ tema deve ser algo que o autor domine. $\mathrm{O}$ autor de um texto deve conhecer o suporte em que seu texto será veiculado, bem como o contexto em que aquilo que produziu estará inserido.

É importante salientar que o suporte não é apenas um modo de transporte e fixação, mas interfere no discurso. Cada gênero exige um suporte específico para sua circulação. Com relação aos gêneros produzidos pelos adolescentes no projeto, notava-se uma preocupação da professora com a sua circulação, mesmo que restrita aos alunos do projeto, exceto no caso da produção do Jornal, este com tiragem para toda a escola. Dessa forma, das várias atividades de produção escrita vivenciadas pelos alunos e professora, foi produzido um anúncio, na metade de uma folha de papel, e afixado no mural da sala do projeto; um bilhete também foi escrito, na metade de uma folha de papel, e depositado em uma caixa, e, posteriormente, entregue aos alunos. Também foi produzida a descrição/criação de um personagem, em folha de papel, organizada, revisada, encadernada e disponibilizada na biblioteca da sala.

Ao contrastar a prática do projeto e a prática regular do $3^{\circ}$ ciclo, a partir do discurso dos adolescentes, nota-se, naquela para a qual não foi definido o gênero textual e que teve como função meramente 
"ganhar ponto"; com pouca mobilização do sujeito para a escrita, sem considerar sua função social, com tempo e laudas delimitados, mesmo que o aluno aprenda "na base da chicotada", ele aprenderá, talvez, a escrever ortograficamente as palavras e organizar as orações no período, ou seja, aspectos relacionados às unidades da língua (palavras e orações). Segundo Bakhtin (2003 p. 305), "as unidades significativas da língua - a palavra e a oração por sua própria natureza são desprovidas de direcionamento, de endereçamento - não são de ninguém e a ninguém se referem". A partir do momento em que a palavra ou a oração está endereçada, direcionada, temos diante de nós um enunciado.

Diante do exposto, o desafio da escola é elaborar propostas de produção textual que mais se aproximem do contexto real, ou seja, é preciso criar situações autênticas de produção textual, que provoquem nos adolescentes boas razões para escrever. A seguir, vamos apresentar dois gêneros textuais lidos e produzidos na sala de aula do projeto e apontar os limites e as possibilidades geradas pelas atividades na formação de alunos produtores de texto.

\section{ESCREVER ANÚNCIOS NA ESCOLA: PARA QUÊ?}

$\mathrm{Na}$ comunidade em que vivem os adolescentes pesquisados era comum a presença de anúncios de produtos e serviços variados, cuja função estava clara: vender um serviço ou um produto. Os suportes eram variados e não se restringiam ao jornal, mas também eram usados os muros, as placas improvisadas, os folhetos, as janelas das casas e os automóveis. Trata-se de um gênero de circulação intensa no contexto social dos adolescentes, sujeitos desta pesquisa.

Considerando, então, o anúncio como um gênero de grande circulação no contexto social dos centros urbanos e na comunidade onde residem os estudantes-adolescentes, a professora do projeto propôs a leitura de vários anúncios, em seu suporte original, e a discussão sobre os produtos anunciados na comunidade. Em seguida a professora solicitou que os alunos escrevessem um anúncio, estruturado na forma de classificados.

As atividades desenvolvidas por ela, para a produção do anúncio, podem ser assim descritas: oferecer um modelo do gênero a ser produzido em seu portador autêntico, realizar a leitura desse texto, destacar seus traços distintivos, apresentar as condições de produção, solicitar a leitura do texto produzido, devolver a produção revisada para a realização da versão final, reler o texto em voz alta e sentir a reação da audiência e, finalmente, expor os anúncios produzidos no mural. 
Constatou-se que os alunos responderam adequadamente à proposta de produção textual sugerida pela professora, no que se refere à estrutura do gênero anúncio, considerando que a principal característica desse gênero está relacionada à intenção persuasiva, ou seja, o texto procura despertar no interlocutor o desejo de comprar algo, seja um produto, uma ideia, ou aderir a uma causa. Para alcançar esse objetivo, é preciso desenvolver uma capacidade para elencar traços distintivos do produto ou serviço que se deseja vender, habilidade para seduzir o leitor/cliente de que seu produto é de boa qualidade e indicar o contato.

A Produção escrita 1, apresentada na Figura 1, - ainda na sua primeira versão - mostra as habilidades linguísticas do adolescente na estruturação do texto. Os problemas encontrados são de natureza ortográfica, como por exemplo, a influência da oralidade na escrita (vendici/vende-se; conpreta/completa; miu/mil; valo/valor), erros provenientes do desconhecimento de regras contextuais (emprego do $\mathrm{m} / \mathrm{n}$ - conpreta/completa), apagamento do verbo no infinitivo (-r) trata/tratar, ausência da marcação da nasalidade (anucio/anúncio).

FIGURA 1 - Produção escrita 1: anúncio

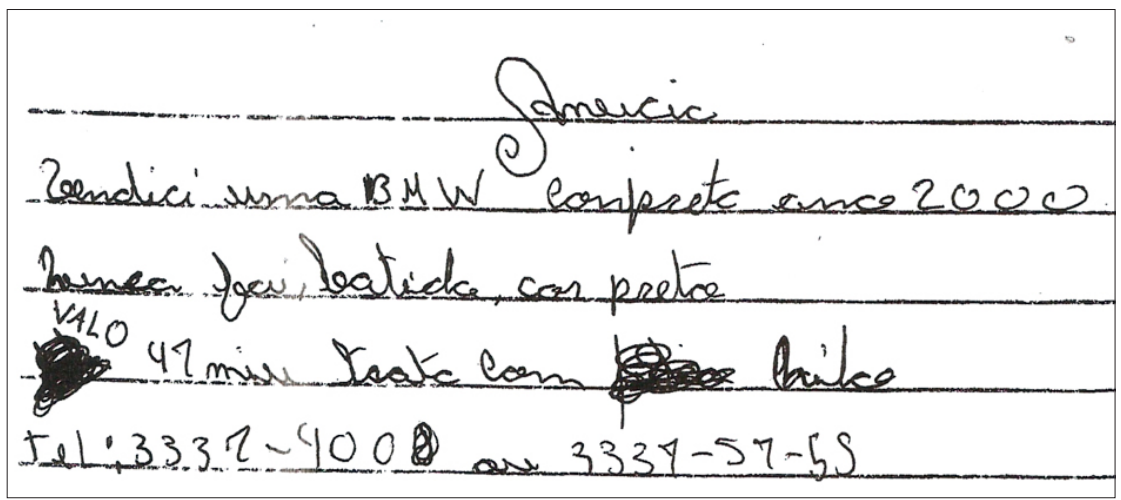

Fonte: Dados da pesquisa.

No momento da revisão, a professora percebeu um toque de humor em alguns textos e, então, teve a ideia de propor aos alunos que elaborassem "anúncios humorísticos". A leitura dos "anúncios humorísticos" produzidos pelos alunos gerou um ambiente descontraído e agradável na sala de aula. Foi possível constatar, com relação à postura da professora, que, ao invés de desconsiderar ou reprimir as produções dos anúncios que apresentavam um toque de humor e fugiam da função social de um anúncio - vender um 
produto ou um serviço -, ela aproveitou a situação para criar uma possibilidade de aprendizagem na sala de aula e modificou a função social do texto: no anúncio original a intenção era vender um produto, agora o texto tem a intenção de gerar o riso.

Marcuschi (2002) aponta que os gêneros textuais são estruturas relativamente estáveis e descreve o fenômeno da "intertextualidade intergêneros", ou seja, uma configuração híbrida que um gênero textual pode assumir. Como no caso dos "anúncios humorísticos", sugeridos pela professora, a estrutura utilizada é a dos anúncios, mas a função é do gênero piada.

Com a transformação do gênero anúncio em "anúncios humorísticos", mesmo mantendo a estrutura do anúncio, a produção escrita ganhou uma nova significação, uma vez que passou a fazer sentido para os adolescentes - gerar o riso, a descontração, cumprindo uma função em uma dada situação comunicativa.

Em seguida, na Figura 2, apresentamos um dos "anúncios humorísticos" mais comentados entre os adolescentes, após a sua inclusão no mural, considerando o entretenimento gerado tanto pelo texto quanto pelo desenho (produção escrita 2).

FIGURA 2 - Produção escrita 2: anúncio humorístico

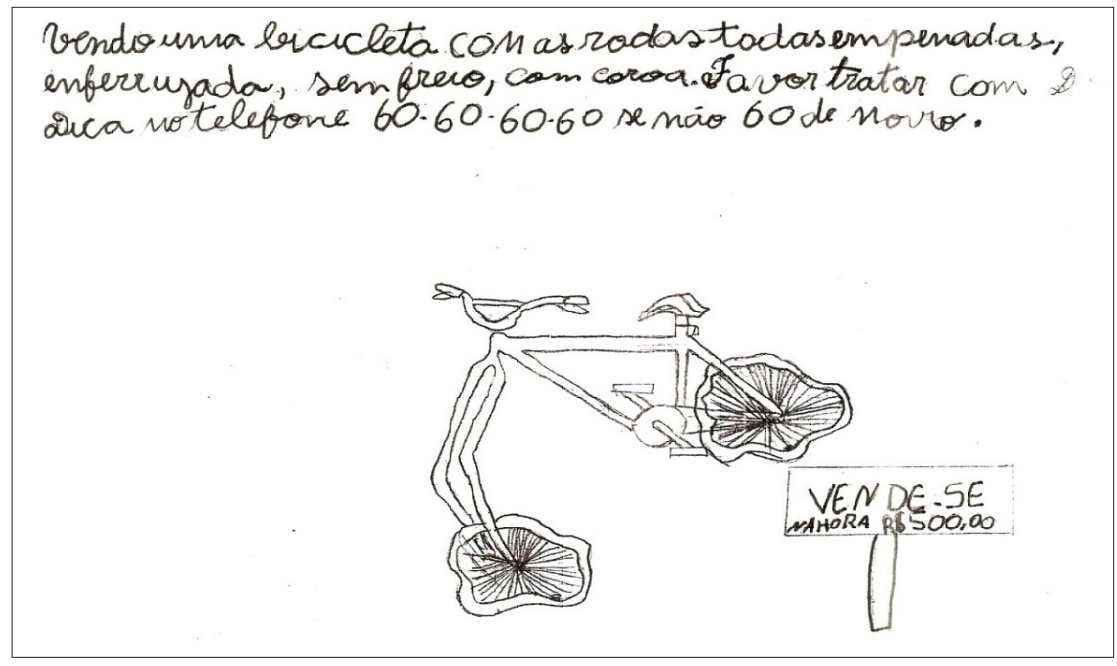

Fonte: Dados da pesquisa.

No processo de hibridização dos gêneros anúncio/piada, encontramos, na produção acima, marcas discursivas utilizadas para gerar o riso: o número do telefone com repetição do numeral 60, com 
sentido de "cê senta" (você assenta e espera); o preço discrepante considerando o estado de (não) conservação da bicicleta, que mostram não se tratar de um anúncio comum, indicando que algo foi modificado.

O evento evidencia a hibridização do gênero - anúncio com a piada -, nos textos produzidos pelos adolescentes em situação incentivada pela professora, com o intuito de atribuir sentido aos textos produzidos na escola. Considerando a flexibilidade e a dinamicidade dos gêneros, conclui-se que os adolescentes criaram um gênero textual híbrido: "anúncio humorístico".

Essa plasticidade atribuída aos gêneros textuais está relacionada ao fato de que eles são fenômenos históricos vinculados à vida social e cultural. Um exemplo bem conhecido dessa transmutação entre gêneros é o e-mail, que tem as cartas e os bilhetes como seus antecessores. Também na literatura é comum encontrar a "intertextualidade intergêneros": o poema "Classificados poéticos" de Roseana Muray (2010) é um exemplo desse fenômeno. A autora lança mão da estrutura dos classificados para criar um texto poético. Outro exemplo é o poema "Receita para fazer um herói”, de Reinaldo Ferreira (2015):

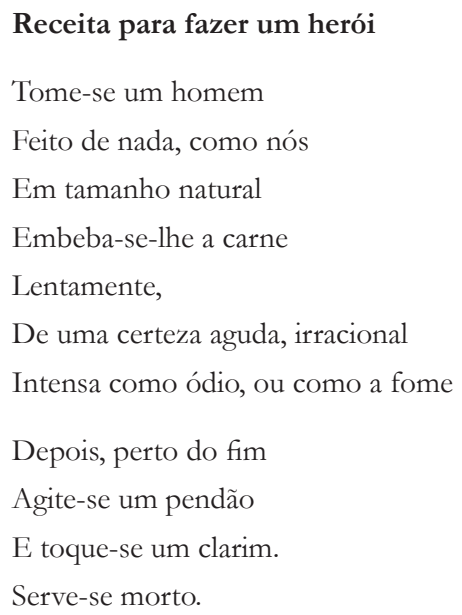

Nesse caso, a estrutura composicional é a da receita culinária, que explicita os ingredientes necessários e o modo de fazer, e é finalizada com uma sugestão do tipo de acompanhamento, como aparece costumeiramente nas receitas culinárias. Contudo, não se trata de uma receita, mas de um poema; o uso da estrutura da receita foi crucial para gerar um efeito de sentido; não foi à toa que o autor escolheu esse gênero.

É importante ressaltar que os exemplos, citados anteriormente, de gêneros textuais híbridos - "Classificados poéticos" e "Receita 
de herói" - não foram lidos na sala de aula do projeto. No caso dos "anúncios humorísticos" produzidos pelos adolescentes, o contexto foi um pouco diferente: a proposta partiu da professora, considerando a familiaridade do gênero anúncio, contudo, a produção de anúncios fictícios não foi aceita pela maioria dos adolescentes. Assim, alguns deles, "aproveitaram" da estrutura do gênero anúncio, que exige a descrição dos objetos que se quer vender, para transgredir e descrever os objetos de forma inusitada, com a função de gerar o riso. Desse modo, o "anúncio humorístico" produzido pelos adolescentes, apesar de manter a estrutura composicional do anúncio, não mais cumpria a função de vender um produto, que é a finalidade almejada nos textos da esfera publicitária, mas trouxe a proposta de exploração do humor. Portanto, o que define o gênero textual, nesses casos, é a função e não a forma, exigindo do leitor a capacidade de descobrir a função dessa forma não esperada.

\section{ESCREVER BILHETES NA ESCOLA: PARA QUÊ?}

O evento de letramento apresentado a seguir refere-se à escrita de bilhetes para os colegas. Esse evento pode ser dividido em três subeventos: lendo, ouvindo e interpretando a letra da música "ECT" de Carlinhos Brown; informando sobre o preenchimento de um envelope; apresentando as condições de produção para a escrita do bilhete.

Com as carteiras dispostas em círculo, a professora entregou uma folha com a letra da música; leu o texto e alguns alunos acompanharam a leitura silenciosamente; outros cantarolavam e dançavam na carteira; dois alunos ainda estavam dispersos, brigavam e trocavam socos e pontapés. Após intervenção da professora, todos os alunos se envolveram com a atividade e acompanharam a canção, que foi reproduzida no leitor de CD. Alguns adolescentes cantaram junto, principalmente o refrão. Depois, a professora perguntou sobre o tema da música e vários alunos se manifestaram. Após vários comentários, os alunos concordaram que o tema da música era "uma carta de amor". A professora confirmou a resposta e socializou a questão feita por um colega sobre o significado da sigla ECT (Empresa Brasileira de Correio e Telégrafos). Sem uma resposta adequada dos alunos, a professora interveio e explicou o significado da sigla ECT e indicou as funções da empresa e aproveitou para indagar sobre os procedimentos necessários para se enviar uma carta.

Após a discussão referente ao contexto da música, a professora entregou outra folha, contendo modelos de vários bilhetes, que foram 
produzidos para o jornal da escola. Entretanto, como a demanda era elevada, nem todos puderam ser publicados na seção "recadinhos". Com a intenção de mobilizar os alunos para a produção dos "recadinhos", a professora propôs a organização do "correio amigo". Destarte, a leitura em voz alta dos "recadinhos" serviu como modelo para a escrita dos bilhetes que seriam produzidos pelo grupo. $\mathrm{Na}$ sequência, a professora esclareceu o que os alunos deveriam fazer, relembrou os exemplos de bilhetes oferecidos como modelos, enfatizando que não poderiam ser copiados. Reforçou, também, a questão de que, no texto, não deveria aparecer brincadeira de mau gosto. A professora define, então, o que é aceitável do ponto de vista da forma e do conteúdo. O suporte oferecido para a produção foi a metade de uma folha de ofício e, após o término da produção, os bilhetes deveriam ser postados na caixa e, posteriormente, entregues aos destinatários.

Nos bilhetes produzidos, notamos que os adolescentes procuravam expressar as atitudes do colega que não lhes agradavam, restabelecer relações de amizade, xingar ou demonstrar afetos. Observase que, na Produção 3 (Figura 3), a adolescente coloca a palavra "chata" entre parênteses, utilizando o recurso linguístico de forma não apropriada, uma vez que, do ponto de vista gramatical, utilizamos os parênteses para fazer um comentário ou explicação a respeito do que se escreveu; aqui o recurso linguístico mais apropriado seriam as aspas, que são usadas quando se quer ressaltar uma palavra, que parece ser o caso. Uma hipótese para o uso dos parênteses pode ser para mostrar à professora que a palavra "chata" não está sendo usada para xingar a colega, diante da solicitação da professora de não escrever nada de mau gosto.

FIGURA 3 - Produção escrita 3: bilhete

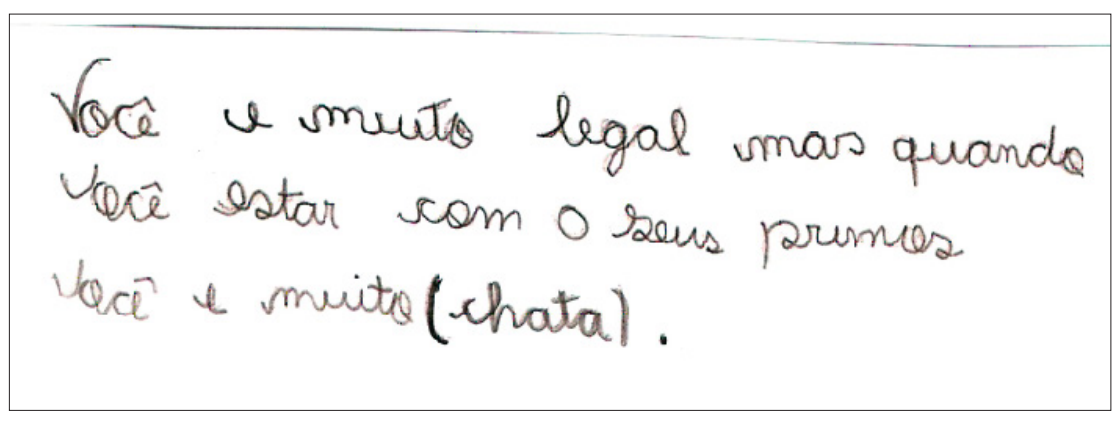

Fonte: Dados da pesquisa.

Para Maingueneau (1997, p. 91), as aspas servem, de certa forma, "para proteger-se antecipadamente de uma crítica do leitor, que, 
supostamente, esperará um distanciamento frente a essa determinada palavra". É como se o autor do texto assumisse que aquela palavra merece uma atenção especial e pode marcar ironia. No exemplo, considera-se que a adolescente estava escrevendo um bilhete para sua amiga e não queria magoá-la. Então, o recurso utilizado foi de, inicialmente, apontar que sua amiga é legal e, posteriormente, inserir sua opinião no que se refere às atitudes da amiga quando está com seus primos.

Já na Produção 4 (Figura 4), a intenção da autora é enfatizar a importância da amizade, mostrar que a colega é especial e que a "todo tempo e a toda hora está por perto", e expressa seu desejo de que a colega nunca se afaste, evidenciando, assim, a sua capacidade discursiva, na escolha das palavras que exprimem a intensidade de seus sentimentos de amizade. Também notamos, no texto da adolescente, algumas dificuldades na ortografia, por exemplo, o desconhecimento de regras contextuais (uso c/ç - espeçiau/especial); ausência da marcação da nasalidade (nuca/nunca); trocas de letras (d/t - pedo/perto); omissão de letras relativa à composição de sílabas complexas (pedo/perto).

FIGURA 4 - Produção escrita 4: bilhete

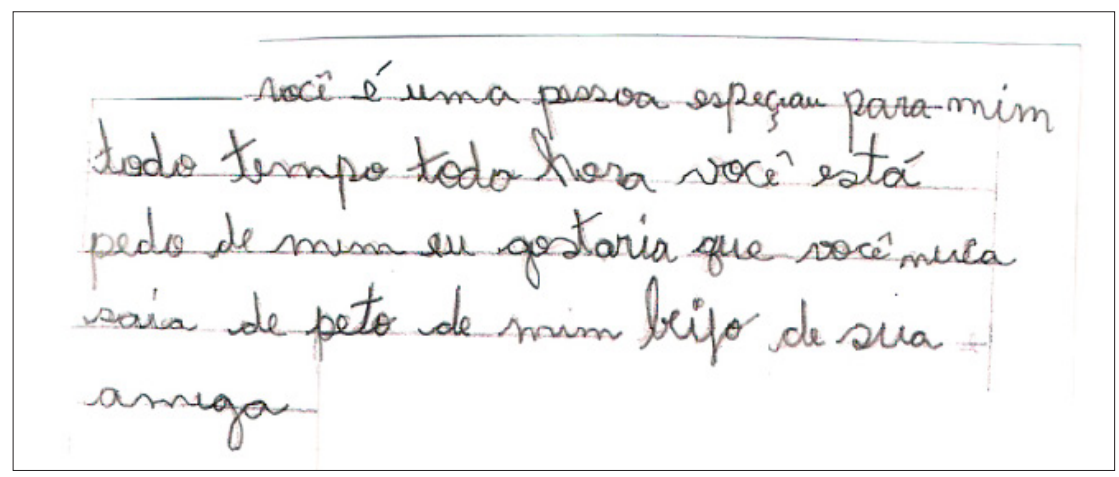

Fonte: Dados da pesquisa.

Apesar das dificuldades ortográficas apresentadas na Produção 4 , concluímos que o bilhete produzido pela adolescente cumpriu a função de demonstrar afetos e está inserido adequadamente no domínio discursivo interpessoal.

Diante do exposto, os adolescentes assumiram uma postura protagonista e ressignificaram o uso do bilhete, que usualmente tem a função de promover uma informação objetiva quando o interlocutor está ausente. Diante da proposta da professora de produzir bilhetes para os colegas de sala, com quem se encontravam diariamente e, por 
esse motivo, as informações objetivas poderiam ser dadas a partir da interação face a face, os adolescentes buscaram outra função para o bilhete: um modo de expressar afetos e desafetos.

Os exemplos destacados demonstram que os adolescentes procuram significar seu discurso e estabelecer uma interlocução (letramentos críticos e protagonistas), considerando que

a linguagem não ocorre em um vácuo social e que, portanto, textos orais e escritos não têm sentido em si mesmos, mas interlocutores (escritores e leitores, por exemplo) situados no mundo social com seus valores, projetos políticos, histórias e desejos constroem seus significados para agir na vida social. (ROJO, 2009, p. 108)

A partir da análise das ações da professora e dos alunos no evento de letramento "escrevendo bilhete para os colegas", percebese que a professora procurou orientar-se por uma concepção de ensino de língua calcada nos princípios da interação e dos usos sociais da escrita. A professora partiu do interesse dos adolescentes pela escrita dos "recadinhos" produzidos para o jornal da escola, que tinham a função de deixar registrada uma mensagem em um suporte que circulava na escola. Quando a professora, apesar de solicitar a produção de um mesmo gênero textual - o bilhete - alterou as condições de produção, ela modificou também os sentidos dessa produção. $\mathrm{Na}$ escrita para o jornal, o interlocutor era escolhido pelo adolescente; no "correio amigo" os interlocutores eram sorteados, ou seja, nem sempre se tinha algo a dizer. Análise semelhante é feita por Maciel e Lúcio (2008), diante de uma atividade de escrita de cartas no contexto escolar em que os alunos procuram a todo custo dar sentido às atividades escolares ou transgredi-las. Nesse trabalho, tendo em vista o paradoxo vivido pelo professores que buscam alfabetizar letrando por meio da exploração de gêneros textuais variados, as autoras indagam: "como criar, na sala de aula, condições de produção, uso e circulação de textos que sejam similares àquelas vivenciadas nas situações sociais que ocorrem fora do espaço escolar, nas diversas situações reais de uso da escrita? (MACIEL; LÚCIO, 2008, p. 30)

Desse modo, a análise das produções escritas realizada neste estudo indica que os alunos produzem e respondem a propostas de produções escolares, mas também que eles, quando têm liberdade para se expressarem, não deixam de apresentar críticas ao modelo de letramento escolar, alterando propositalmente o que lhes foi solicitado, tal como fizeram na produção do anúncio, dando um toque de humor e do "bilhete amigo", nem sempre escrito de forma amigável.

As produções dos alunos do projeto nos levam a refletir que, apesar do avanço no processo ensino e aprendizagem quando 
se prioriza o trabalho com os gêneros textuais, é muito importante considerar as intenções de cada gênero textual e suas manifestações culturais e ideológicas sem nos deixar levar pelo excesso da pedagogização do letramento. É importante observar quais os gêneros textuais são mais adequados para a leitura e a produção na escola, sem, contudo, romper com suas finalidades interativas.

\section{REFERÊNCIAS}

ANDRÉ, M. E. D. A. de. Estudo de caso em pesquisa e avaliação educacional. Brasília: Líber Livro, 2005. BAKHTIN, M. Estética da criação verbal. São Paulo: Martins Fontes, 2003.

BAKHTIN, M. M.; VOLOCHÍNOV, V. N. (1929). Marxismo e filosofia da linguagem. 4. ed. São Paulo: Hucitec, 1988.

BRASIL. Ministério da Educação. Instituto Nacional de Estudos e Pesquisas Educacionais Anísio Teixeira (INEP). MEC E Inep comentam resultados do Enem 2014. Disponível em: http:/ / www.brasil.gov.br/educacao/2015/01/mec-e-inep-apresentam-resultados-do-enem-2014. Acesso em 3 dez.2015.

FAIRCLOUGH, N. Discurso e mudança social. Brasília: Editora Universidade de Brasília, 2001. FERREIRA, Reinaldo. Receita para fą̧er um herói. Disponível em: < http://www.escritas.org/ pt/livro/reinaldo-ferreira>. Acesso em: 3 dez. 2015.

GERALDI, J. W. Portos de Passagem. São Paulo: Martins Fontes, 1997.

GOLDMAN, M. Os tambores dos mortos e os tambores dos vivos: etnografia, antropologia e política em Ilhéus, Bahia. Revista de Antropologia, São Paulo, USP, v. 46, n. 2, p. 446-475, 2003.

HEATH, Shirley B. Protean shapes in literacy events: ever-shifting oral and literate traditions. In: TANNEN, D. Spoken and written language: exploring orality and literacy. Norwood, N.J. : Ablex, 1982, p. 91-117.

HEATH, Shirley B. Ways with words: language, life and work in communities and classrooms. Cambridge: Cambridge University Press, 1983.

KLEIMAN, A. Modelos de letramento e as práticas de alfabetização na escola. In: Os significados do letramento. Campinas: Mercado de Letras, 1995. p. 15-61.

MACIEL, F. I. P.; LÚCIO, I. S. Os conceitos de alfabetização e letramento e os desafios da articulação entre teoria e prática. In: CASTANHEIRA, M. L.; MACIEL, F. I. P.; MARTINS, R. M. F. Alfabetização e letramento na sala de aula. Belo Horizonte: CEALE; Autêntica, 2008.

MAINGUENEAU, Dominique. Novas tendências em análise do discurso. Campinas: Pontes, Editora da Universidade Estadual de Campinas, 1997.

MARCUSCHI, L. A. Gêneros textuais: definição e funcionalidade. In: DIONISIO, A. P.; MACHADO, A. R.; BEZERRA, M. A. (Orgs.). Gêneros textuais e ensino. Rio de Janeiro: Lucerna, 2002. p. 19-36.

MURRAY, Roseana. Classificados poéticos. São Paulo: Editora Moderna, 2010.

ROJO, R.; CORDEIRO, G. S. Apresentação: gêneros orais e escritos como objetos de ensino: modo de pensar, modo de fazer. In: SCHNEUWLY, B.; DOLZ, J. Gêneros orais e escritos na escola. Campinas: Mercado das Letras, 2004. p. 7-18. 
ROJO, R. Letramentos múltiplos, escola e inclusão social. São Paulo: Parábola, 2009.

SCHNEUWLY, B.; DOLZ, J. (Col.). Gêneros orais e escritos na escola. Campinas: Mercado das Letras, 2004.

SOARES, M. Letramento e escolarização. In: RIBEIRO, V. M. (Org.). Letramento no Brasil. São Paulo: Global, 2003. p. 89-113.

SPRADLEY, J. P. The etnograpphic interview. New York: Holt; Reinhart; Winston, 1979.

STREET, X. What's “new” in New Literacy Studies? Critical approaches to literacy in theory and practice. Current Issues in Comparative Education, London, Kings College, v. 5, n. 2, p. 77-91, may. 2003.

THIES, V. G.; PERES, E. Quando a escrita ressignifica a vida: diários de um agricultor uma prática de escrita masculina. Revista Brasileira de Educação, Rio de Janeiro, v.14, n. 41, p. 216-231, mai./ago. 2009.

\section{NOTAS}

${ }^{1}$ Atualmente, o projeto é denominado Programa Escola Integrada (PEI), desenvolvido pela SMED/BH.

${ }^{2} \mathrm{Na}$ Rede Municipal de Ensino de Belo Horizonte, desde a implantação do projeto denominado "Escola Plural", em 1995, os ciclos de formação humana estão organizados da seguinte forma: 1o ciclo, envolvendo os alunos entre 6 e 8 anos; 20 ciclo, denominado ciclo da pré-adolescência, compreendendo os alunos entre 9 e 11 anos e o 3 o ciclo, englobando os alunos adolescentes entre 12 e 14 anos.

${ }^{3}$ Research in NLS challenges this view (autonomus) and suggests that in practice literacy varies from one context to another and from one culture to another and so, therefore, do the effects of the different literacies in different conditions. The autonomous approach is simply imposing western conceptions of literacy on to other cultures or within a country those of one class or cultural group onto others.

${ }^{4} \mathrm{O}$ conceito de autoria utilizado por Geraldi (1997, p. 15-16) se coaduna com a concepção de sujeito. "Elegendo o trabalho dos sujeitos como fio condutor da reflexão, pretende-se afastar também qualquer interpretação que tome o sujeito como a fonte dos sentidos. Entre o tudo (produtor único dos sentidos) e o nada (assujeitamento completo a uma estrutura sem frinchas), há uma prática cotidiana em que os sujeitos não podem ser concebidos como 'autônomos sintáticos, monstros da gramática' e também - e no mesmo sentido - não podem ser concebidos como meros portadores da hegemonia discursiva de seu tempo".

Recebido: $25 / 04 / 2014$

Aprovado: 06/08/2015

Contato:

Universidade Federal de Minas Gerais Faculdade de Educação Av. Antônio Carlos, 6627, Pampulha Belo Horizonte $|\mathrm{MG}|$ Brasil CEP 31.270-901 